\title{
George Nash and Andrew Townsend eds, Decoding Neolithic Atlantic \& Mediterranean Island Ritual
}

\author{
Oxford, UK: Oxbow Books (2016). Hardback, 365pp, black/white \\ illustrations. ISBN 9781785700507. $£ 50$.
}

\section{Tore Lomsdalen \\ University of Malta \\ tore.lomsdalen.15@um.edu.mt}

The use of the term "decoding" in the title of this volume recalls another book, famous in archaeology's history: Gerald Hawkins' Stonehenge Decoded (1965; UK edition 1966). That publication was met with immediate harsh criticism from British archaeologists such as Atkinson (1966) and Hawkes (1967). This was not only for its archaeoastronomical content, but also for using the word "decoding", which implied that Hawkins had deciphered and found the ultimate solution as to why Stonehenge was built. This publication does not use the word "decoded", but a sublime variation, namely "decoding". The latter denomination opens the possibility for a continuous deciphering, which this volume rightly does. Nevertheless, the word "decode" in any form is rather questionable in the title of a scholarly publication; it is more appropriate to popular literature.

The 16-chapter book edited by George Nash and Andrew Townsend here under consideration gives an attractive insight into the Neolithic mindset as regards how individuals engaged in constructing social environments and organisations. Various papers explore the level of insularity of islands and island groups within the Atlantic and Mediterranean region, some of which are located on a continental shelf, probably having been a part of a mainland during periods of considerably lower sea levels. However, the sequence of the chapters could have been organised more conveniently in a more natural geographical flow.

The volume starts with an explanatory introduction by the editors. Sadly, Andrew Townsend passed away during the final editing stage, and so the publication is dedicated to his memory. The introduction sets the scene for the conceptual context of what kind of space an island is - more than merely a rock or piece of land in a sea or ocean. They argue that an island becomes a place when its space is described in terms of topography and its resources - the concept of "islandscape" is explained in the context of human participation in creating an insular character through long-term cultural traditions. The 
editors' intention is not to produce a volume bringing together traditional views about Neolithic insularity, but to present the reader with a series of thought-provoking papers to emphasise a more holistic view of ritual island-life in the Neolithic (p. xiv). This is generally described in an engaging way throughout the volume. How much emphasis is put on thought-provoking interpretation, on the other hand, is more variable from chapter to chapter.

The first chapter, "Collective Spaces and Material Expressions: Ritual Practice and Island Identities in Neolithic Gotland", starts with research by Paul Wallin and Helene Martinsson-Wallin into ritual practice and island identities in Neolithic Gotland in the Baltic Sea. Burial rituals and practices had a regional expression, but there seems to be a clear diversification within the various local territorial island areas. Whether these mortuary practices were a part of a holistic view or belief system is not mentioned. Nevertheless, the possibility cannot be excluded, as individuals were buried with artefacts and grave goods reflecting the local environment and social hierarchies (p. 11). Seals were also ritually butchered at so-called "seal altars" (p.7). Further, in a cosmological context it is engaging to observe that buried individuals and monuments from the Late Neolithic up to the Viking Age were generally placed in a north-south direction, deviating about $10-20^{\circ}$ clockwise from the cardinal points (p. 2).

In Chapter 2, "Monuments from the Doorstep: Exploring the Temporal, Spatial and Social Relationship between Chambered Cairns and Settlements during the Orcadian Neolithic", we move to the Orkney Islands. Christopher J. Kerns carries us through a thoroughly detailed chronological study of Orcadian Neolithic settlements and chambered cairns, and considers both typologies and stratigraphic sequences, supported by Bayesian statistical probability modelling (p. 19). The chapter also brings a detailed study of spatial pattern between local settlements and chambered cairns through a GIS set of cumulative viewshed and visibility analysis. Several engaging cosmologies are discussed (pp. 47-49), one related to the ancestral connotation of intervisibility between burial monuments and settlements in the landscape, as well as a possible intentional separation of the two by creating geographical distance. The author also takes the sky into account, suggesting that the engineering of the intervisibility between the settlements and the chambered cairns is comparable with the astronomical alignments associated with monuments such as Maes Howe and the Ness of Brodgar (p. 44).

Gary Robinson takes us to the largest island in Wales, Ynes Môn or Anglesey, in Chapter 3, "An Island Archaeology of Neolithic Ynes Môn (Anglesey)". In the Neolithic, Anglesey was not physically isolated from the mainland, and consequently it cannot be classified as inherently insular. To establish a possible Neolithic territorial integrity, Robinson sensibly bases his research on typology. He compares regional pottery and burial structures across the Irish Sea and Britain, suggesting a connected identity, and he argues that Anglesey in the Neolithic was a product of social choices distinct from the mainland societies, and that its people established their own unique island identity ( $p$. 61) - a conclusion that is not entirely convincing.

In Chapter 4, "Uniformity and Uniqueness: The Extraordinary Scillonian Entrance Graves", Laurie Waite takes us further south along the British coast to the Isles of Scilly. It 
is striking and extraordinary that this small archipelago contains almost 100 chambered burial-ritual monuments (in various conditions), classified as "entrance graves". In the context of the limited evidence of Mesolithic and Early Neolithic occupation, this of course raises the question of whether this was an "island for the dead"; a denomination Waite classifies as a "complete misnomer" (p. 66). On the other hand, it seems that Scilly was settled by Cornish migrants only around 2000 BC (p. 76). The absence of stratigraphic evidence and radiocarbon dates makes it difficult to establish a reliable chronology ( $p$. 65). Waite compellingly studied 67 sites on six islands, concentrating on the morphology of the monuments, including their architectural attributes, landscape setting, spatial distribution and orientations (p. 69). This study shows that the Bronze Age cists on North Hill all oriented north-south and the grave entrances either east or uphill to the North Hill " $E$ " monument. Waite concludes that the rising of the Sun was a secondary matter (p. 73). This is another statement that is not altogether convincing, given that the graves were oriented towards the rising of the Sun. A more conclusive argument on orientation is that all entrance grave openings turn their back towards the sea. This could suggest an interactive dynamic between landscape and seascape - two out of three probable elements in an islander's cosmology, where the sky could very well have been the third one.

We must jump ahead to Chapter 8, "Defying Expectations: Neolithic Life in the Isles of Scilly", to find another paper on the Isles of Scilly. In contrast to Waite, who concludes that Scilly had an apparently limited contact from overseas (p. 78), Trevor Kirk argues that due to its strategic position, Scilly was a possible transition point in the western seaways during the fifth and fourth millennia BC between northwest France, southern England, southern Ireland, Wales and all the way up to Orkney and Shetland (pp. 126-127). Even with limited archaeological evidence from the Scillonian Neolithic period, Kirk concludes that it is feasible to draw a general outline of Scilly's relationship with other communities in the western seaways (p. 135).

Paul-David Driscoll opens three chapters on the Channel Islands off the coast of Normandy with Chapter 5, "Ritual Competition in the Final Neolithic of the Channel Islands". He analyses the mechanism of intra-island competition between the different communities by claiming a site of special interest even if another community had also done so. The five Channel Islands mentioned in this chapter indicate that ritual practice was not homogeneous, nor subject to a transition process, but contemporary practices happening at the same time and sometimes even at the same site (p. 90). The only connection Driscoll mentions between burial practice and a possible belief system is by the creation of new monuments, which at the same time is a new way of connecting to the ancestral past (p. 91). This is an engaging paper on how a small archipelago creates new insular identities, even while being heavily influenced by external stimuli.

Chapter 6, "Establishing a Diverse Architecture: Contextualising the Delancey Park Gallery Grave, North-east Guernsey", by George Nash, concentrates on the morphology of gallery graves on the Channel Islands and less on mortuary rituals and burial practices. He carries us through a detailed analysis and excavation programme and history; the gallery grave tradition is confined to about 40 extant monuments and is geographically 
restricted to northern France and the Channel Islands (p. 101). Outside this area, there are only two extant, both in Wales. From an archaeoastronomical point of view it is interesting to note that the tradition of orientation for both passage and gallery graves within the Channel Islands is "arguably similar", being along either an east-west or a north-south alignment (p. 103). Nash encompasses orientation into a hybridisation of mortuary design, without discussing the possible cosmological implications.

The last chapter from the Channel Islands, "Re-Viewing the Megaliths of Northern Guernsey" by Kevin Jelly, takes a landscape and phenomenological approach to the megaliths of northern Guernsey. The paper uses digital elevation reconstructions with the GIS cumulative viewshed tool to identify afforded intervisibility and seaview from megalithic sites and symbolically significant natural features. "Afforded" is a key word here: it contextualises the human experience and relationship with the total environment in a holistic consideration (p. 112). Only megalithic sites with a known orientation from their structural entrance are considered. From an archaeoastronomical and skyscape perspective it is noticeable that out of 22 applicable megalithic sites, 12 are oriented east-west, four north-south and two have both orientations. Six sites are listed as "unknown" (p. 114). With such a high statistical significance between megalithic monuments and cardinal orientations, it is unfortunate that this is not further discussed, especially when Jelly draws in a possible Les Fouaillages lunar azimuth (p. 115).

Chapter 9, "Rite to Memory: Neolithic Depositional Histories of an Adriatic Cave", by Timothy Kaiser and Stašo Forenbaher, brings us in one jump across Europe to the Dalmatia archipelago in Croatia. The authors present an elaborate and detailed excavation report of Grapčeva Cave situated at the island of Hvar. Structured deposit evidence indicates ritual activities such as offerings, feasting and secondary burials between approximately 4800 and 4300 BC, when this cultural practice inexplicably ceased (p. 153). However, sporadic human visits to the cave seem to go back to 5900 BC, contemporary with the introduction of farming in the area. Kaiser and Frenbaher mention cosmology while referring to other authors (p. 155). On the other hand, offerings to the supernatural and symbol-laden feasts with meat, medical plants and aromatic herbs used as incense seem to be a part of local culture (pp. 153-155). It can be inferred that these rituals may very well be embedded in a worldview, belief system or cosmology. As there is comparatively little evidence of the social dynamic of central Dalmatia, the authors turn to the western side of the Adriatic, namely Italy, for "informative analogies" (p. 156).

The human capability to process spatial knowledge and external symbolic storage at complex levels has existed at least as far back as the Palaeolithic, and appears to be universal to almost all individuals and all societies (Renfrew and Scarre 1998). These theories, sustained in the archaeological record, could be a valid back-drop to Paula L. Lutescu-Jones' Chapter 10, "Moving World: Memory, Mobility and Mortality in the Aceramic Neolithic Cyprus" which deals with how ideals emerge and identities (re)generate in aceramic Neolithic Cyprus between 8500 and 5500 BC. The chapter starts off with analysing the (re-)creation of a new world, along with establishing insular identity in the colonisation process of moving across the seascape from the Levant to Cyprus. However, the chapter unfolds a conglomeration of transformation processes of 
a shared past, temporality of death, material culture as a body, creativity and imagination unfolded through a complex level of memory storage. Lutescu-Jones concludes by arguing that an emotional, spiritual and ideological ethos accompanied the emigrants, shaping their new world in a cosmological context of life and death.

The following Chapter 11, "Ritual and Religion in Neolithic Crete?", by Alan Peatfield, approaches the subject of religion and how it is dealt with in Neolithic Crete. The interesting but challenging argument is that throughout most of the Neolithic period from about 7000 to 3000 BC, Knossos was the only clearly-attested dwelling site on the island. Not only that, there are few indications of religious activity on Crete until the Late-Final Neolithic period and the beginning of the rich complexity of the Minoan Bronze Age civilization. The puzzle is further deepened by the given evidence of religious activities through all these millennia on mainland Greece. Peatfield carries us through an engaging account of East Mediterranean religious activity conceptualised through the ritual material culture of artefacts, mortuary costumes, shrines and sacred sites and landscapes. The insular isolation mystery which remains so today, does justify the "?" in the title.

Jennifer Wexler enchantingly describes her own project examining development and utilisation of rock-cut tombs and mortuary sites in western Sicily (p. 191) in Chapter 12, "Ancestors in the Rock: A New Evaluation of the Development and Utilisation of Rockcut Tombs in Copper Age Sicily (4000-3000 cal BC)". The highlight of the study is that there existed an intimate relationship between habitation and burial sites (p. 199). This is an interesting archaeological argument, however often difficult to corroborate due to lacking supportive evidence of prehistoric dwelling sites. For a reader not familiar to Sicilian prehistoric chronology, Wexler could have presented a separate table indicating the various historical periods (pp. 187-189).

Next port of call is Malta. In the first of two chapters on Malta, "Journeys Through the Underworld in Late Neolithic Malta", Reuben Grima sheds new light on probabilities of how and why the Late Neolithic Malta's Hal Saflieni Hypogeum, a UNESCO World Heritage site, was constructed the way it was through successive stages during the fourth and third millennia BC. That a natural faulting in the rock formation simplified the construction of this underground burial site has long been claimed by archaeologists (p. 202). Nevertheless, Grima's thorough examination of this complex site goes some steps further. His chapter elaborates in a detailed and illustrative manner how the distinct geological formation was intentionally and systematically exploited by orienting a labyrinth of underground chambers, forming the Hypogeum as we see it today (p. 204). To the question of why the builders would utilise the faulty system other than that it facilitated constructional purposes, Grima argues that it emphasises a cosmological and spatial association of the underworld, creating a symbolic boundary between the living and their dead ancestors (pp. 211-212).

Chapter 14, "Searching Beyond the Artefact for Ritual Practices: Evidence for Ritual Surrounding the Unclothed Human Body on Prehistoric Malta during the Temple Period" Andrew Townsend uses the art of the Maltese Temple Period (c. 4100-2400 BC) as a case study to argue that nudity may entail special understanding for some prehistoric societies. This is an exciting but challenging topic. Nudity could be a ritual performance 
by itself or as part of ceremonial practices centred around human fertility. As a part of a temple's or household shrine's ritual practices, the human form in both life and art played a central role. In these cases, emphasis was put on various levels of body exposure encompassed in diverse ideologies (p. 220). Townsend proposes a model regarding ritual nudity indicated by the relationship between anthropomorphic figures, levels of bodily exposure and ritual practice (fig. 14.6, p. 221). Townsend's argument gives the reader much food for thought, and raises questions that deserve to continue to be explored, such as the role of the body and its exposure in the context of wider worldviews.

Island rituals and monumentality are partly outside the scope of the chapter by Keith N. Wilkinson et al.; "The Neolithic in La Balagne, Corsica: An Evaluation using Palynological, Geoarchaeological and Landscape Archaeological Data". Instead, through palynology, geoarchaology and landscape archaeology Wilkinson and his team conduct elaborate research through field studies of the northwest La Balagne area, on how the landscape itself restrained the development of human society on Corsica. The origin of the Neolithic Corsican population gives rise to two theories. One is that new colonists brought with them cultural practices when emigrating from mainland Italy. The other, claims an indigenous development of the first Mesolithic settlers (c. 8600-8300 cal BC) (p. 232). Based on surface-survey palynological data, the paper concludes that because of an absence of Mesolithic sites it was first colonised by Early Neolithic humans (c. 5500-5000 cal BC), who settled into rocky promontories about 20 m above today's sea level. In short, from then on, the following waves of settlers located at higher elevations.

This figurative Neolithic seafaring voyage starting in Gotland ends with Chapter 16, "Houses Fit for Deceased Dwellers: Assessing Architectural Devices within the Rock-Cut Tombs of North-Western Sardinia", by Paula Arosio et al., which researches rock-cut tombs dating back to the Late Neolithic. These impressive mortuary monuments, representing the houses of the dead, are collectively known as Domus de Janus and possess several unique architectural traits (p. 241). They have a series of antechambers for housing the dead and a principal room for ceremonies. Besides being houses of the dead, they also serve as houses for the living, displaying ornamental beams representing timber, bull heads and horns, door lintels and engraved and painted rock-art. The rock-cut tombs were built around a set of primary architectural rules; nevertheless, each monument had its own unique signature (p. 244). The architectural set up, ornaments and symbolic representations do indicate a human day-to-day life with the dead as a part of a complex life/death cycle. This cycle indicates that the house of the dead was not the final resting place, but part of a spiritual or physical voyage towards another dimension.

Concluding thoughts after reading this volume are that it is interesting and engaging. It carries a variety of chapters that in sum give informative input and reflections on what may represent a Neolithic insular identity. Many aspects of it definitely constitute "food for thought" for further investigations into Neolithic insularity and islandscape. On the other hand, the question this reviewer asks himself is "how thought-provoking is this volume really?" After reading, one continues to sits back wondering when will Hawkes' (1954) "Ladder of Inference" reach the sky, if ever? Cosmology, skyscape or celestial orientations will always be physical invisible elements in an archaeological record covering 
prehistory. The only way to make them visible is to infer the material culture with an interpretative archaeology centred around the human element; the earth they live on and the visible sky above them. While there is an ever-growing number of archaeologists who do engage in the topic, as a discipline there is still a long way to go.

The dynamic of a holistic view (or a cosmology) is elaborated as a theme in less than half of the 16 chapters, with most of them lacking a conceptual analogy. Yes, several authors do mention mortuary and other rituals, but only a few contextualise them into a holistic worldview. Even the chapters of the two editors show seemingly no strong enthusiasm for the subject. On a more positive note, the few papers that do contextualise cosmology do so in an engaging and convincing manner, though mostly exclude the observable sky as a part of their cosmology. Some chapters mention orientations and alignments of the Neolithic monumental structures. Whenever so done, it is often vague, undocumented and inconclusive. Despite this, the volume could be a valuable resource for future studies into archaeoastronomy and skyscape archaeology of Neolithic insular archaeological sites. In summing up; it is a worthwhile volume to read. I thoroughly enjoyed it!

\section{References}

Atkinson, R. J. C., 1966. "Moonshine on Stonehenge". Antiquity 40 (159): 212-216. https://doi.org/10.1017/ S0003598X0003252X

Hawkes, C., 1954. "Archeological Theory and Method: Some Suggestions from the Old World". American Anthropologist 56: 155-168. https://doi.org/10.1525/aa.1954.56.2.02a00020

Hawkes, J., 1967. "God in the Machine". Antiquity 41 (163): 174-180.

Hawkins, G. S. with J. B. White, 1965. Stonehenge Decoded. Garden City, NY: Doubleday. https://doi.org/10.1017/ S0003598X00033202

Hawkins, G. S. with J. B White, 1966. Stonehenge Decoded. London: Souvenir Press.

Renfrew, C. and C. Scarre, eds, 1998. Cognition and Material Culture: The Archaeology of Symbolic Storage. Cambridge: McDonald Institute Monographs. 